\title{
Research on the Market Positioning of Electricity Retailers of Power Grid Companies under the New Electric Power Reform
}

\author{
Si Li ${ }^{1, a^{*}}$, Luofei $\mathrm{Wu}^{1, \mathrm{~b}}$ and Dongxiao Niu ${ }^{1, \mathrm{c}}$ \\ ${ }^{1}$ School of Economics and Management, North China Electric Power University, Changping, Beijing, \\ China \\ alis@ncepu.edu.cn, bwuluofei@ncepu.edu.cn, cniudx@ncepu.edu.cn \\ * The corresponding author
}

Keywords: Electricity retailers; power grid companies; Operating environment; Market competition situation; Market positioning

\begin{abstract}
This round of electric power reform opened up the business of electricity sales and actively promoted multi-party capital formation to establish electricity retailers in order to enter the sales market and participate in competition. At the same time, the electricity sales business of the power grid companies will gradually separate and be undertaken by the independent electricity retailers. In this paper, we take the electricity retailers of power grid as research objects, sort out and analyze the current operating environment, discuss and study the market competition situation, and finally put forward the market positioning assumptions. It will clearly define reasonable market position for the new electricity retailers of power grid and have important guiding significance for conducting competitive business effectively.
\end{abstract}

\section{Introduction}

China is gradually advancing a new round of electric power reform and the ultimate goal is to achieve a competitive market for electricity sales, which helps increase market efficiency and optimize resource allocation. The establishment and development of electricity retailers is an inevitable measure to realize the reform of the sales side. To promote the development of the sales market and enhance the core competitiveness of companies, power grid companies must comply with the current market and policy requirements to set up electricity retailers to participate in the electricity sales side. Therefore, in combination with the existing market and competitive environment under the background of the new reform, it is necessary to further clarify the market positioning of the electricity retailers of power grid in order to formulate a reasonable operating mode and achieve long-term development in the market.

At present, domestic scholars mainly study the market positioning of power companies. Reference [1] explored and analyzed the market positioning and development strategy of power supply companies, and pointed out that companies should seek advantages and avoid harm in market shocks. Reference [2] analyzed the impact of electricity marketing on the positioning of power companies. Reference [3] put forward the market positioning of products and services for power supply companies and suggests that they change concepts in order to exploit the market. Reference [4] considered the transformation of the electricity marketing market to the buyer's market and proposed the market positioning of the power companies. Reference [5] took electric power design companies as research objects and sought market positioning based on the characteristics of companies and products.

\section{Operating Environment Analysis}

Policy Environment analysis.

(1) The reform of supply side has made every effort to promote optimal restructuring of the economic structure.

China's economy has shifted from a high-speed growth stage to a high-quality development 
stage and must give priority to quality and efficiency. We should focus on structural reform of the supply side and strive to build an economic system with effective market mechanisms, vibrant macros, and macroeconomic controls, so as to constantly enhance China's economic innovation and competitiveness [6]. In the situation where the ratio of electricity consumption in high-tech industries, strategic emerging industries and modern service industries continues to rise, the industrial electricity consumption structure has undergone major changes and the market environment on the sales side will change with the adjustment of institutions.

(2) Energy revolution promotes the development of comprehensive energy service industry.

The new round of energy revolution involves a wide range of aspects such as economic society, supply of consumption, technology development and institutional mechanisms. Although the scope of coverage is extensive, there are two major development trends in summary. On the one hand, the 'pipeline' and the 'content' chain are independent of each other. On the other hand, the single traditional energy supply shifts to the integrated energy service that based on multiple energy sources. China is actively promoting the transformation of energy-saving technologies, the promotion and application of new energy-saving technologies and new products in order to promote industrial efficiency. The implementation of strategic initiatives such as the substitution of coal consumption, the action plan of green transportation and building construction will surely help increase the proportion of electric energy in the terminal energy market and contribute to the development of an integrated energy service industry.

(3) The mixed reform of state-owned enterprises promotes further reform of the power grid.

Since 2015, China is stepping up efforts to promote the reform of state-owned enterprises and the state grid reform will have even greater and further actions in 2018. In addition to incremental power distribution, the mixed reform will be expanded to other business sections such as manufacturing. In the future, the reform will also explore the establishment of incentive and restraint mechanisms.

(4) The electric power reform has formed a market pattern of multiple buyers and sellers.

This round of reform is structural and overall and has a profound impact on multiple entities in the entire market from different aspects. Among them, the introduction of competition in the sales side and the opening of electricity sales business to social capital are highlights of the reform. The community is full of expectation for the reform dividend, market entities such as local governments, power grid companies, and power generation companies and related social capital have all participated in the reform of the electricity market, forming a diversified market entities.

(5) The competitive electricity sales business of electricity retailers was implemented with asymmetric supervision.

In order to ensure the unity, openness, competition, and orderliness of the electricity market, the state issued relevant documents to clarify the supervision of competitive businesses and the objects of supervision include all members of the electricity market [7]. Among them, electricity retailers of power grid companies are the focus of supervision.

\section{Market Environment Analysis.}

(1) The demand for social electricity has opened up the space for capacity growth in the electricity sales market.

In the 13th Five-Year Plan period, the level of electrification will be further improved during the energy transition. Electricity has the priority of development in the economic development strategies of all countries in the world. In the future and it will also be necessary to maintain high-speed economic development through the input of electricity. There is still huge room to growth in the market capacity of electricity sales.

(2) Energy consumption revolution stimulates the potential of the terminal energy consumer market.

The energy consumption revolution is currently being vigorously promoted, including controlling the total energy consumption, accelerating the clean-up of terminal energy use, and working hard to promote energy efficiency. In particular, in terms of increasing the proportion of electricity consumption, it is necessary to accelerate the electrification of energy in urban and rural 
areas, promote electric energy substitution and accelerate the development of electric vehicles. Meanwhile, it is also necessary to implement substitution of coal by electricity and electricity by oil to increase the level of social electrification. Undoubtedly, the future energy utilization structure will be further optimized. The market demand for terminal energy consumption and market space have great potential.

(3) The positioning transformation of the state grid has broadened the market prospect of integrated energy services. Integrated energy services are set in a more prominent position by the state grid, which is conducive to consolidating the company's target market, expanding its business scope, enhancing new customer service capabilities, driving the development of related industries, fostering new market formats and increasing new benefits. Beyond that, the state grid also requires stronger and better integrated energy service business and will continue to promote the transformation of the company from an energy supplier to an integrated energy service provider, so that the market share will be significantly improved.

(4) Various types of market competition entities have accelerated the planning of the sales market.

Companies intending to enter the market and set up electricity retailers to carry out their business are those mainly in the background of power generation companies, new energy companies, energy conservation service companies and energy internet companies in the fields of power engineering and power equipment. With the continuous deepening of the reform, more and more private enterprises have entered the sales industry. Under the fierce competition situation, the final electricity retailers in the future sales market will either have a solid power supply and user resources or have the ability to provide differentiated value-added services.

(5) The participation of cross-border entities leads to more severe competition.

The opening of electricity market has attracted many parties to participate in the competition. In the process of transformation of the energy industry with a large volume, there may be excellent cross-border entities participate in the competition, which will bring more severe competition with the help of new technologies, new modes and flexible funds.

\section{Market Competition Situation Analysis}

Classification of competitors. In the early days, power grid companies were mainly engaged in electricity sales. However, according to policy of the new electric power reform, in the future, power generation companies, operating incremental distribution network companies, power equipment or energy service companies, cross-border enterprises in Internet, finance, insurance and other industries can all set up power sales companies to participate in market competition [8]. Based on the above investment entities, sales entities on the electricity market can be classified into the following five categories: electricity retailers of power generation companies, electricity retailers of power grid companies, electricity retailers of operating incremental distribution network companies, electricity retailers of power equipment or energy service companies and electricity retailers of cross-border companies.

SWOT analysis of Electricity Retailers of Power grid Companies. The electric reform policies have guided the development direction of the reform and the macroeconomic situation has affected the development of the sales market. The internal factors such as the resources and capabilities of the electricity retailers of power grid companies determine their advantages and disadvantages in the competition. SWOT analysis method is a tool often used in competition analysis and forms the marketing strategy of the company through matching analysis $[9,10]$. A comprehensive analysis of the strengths, weaknesses, opportunities and threats of electricity retailers of power grid companies based on SWOT analysis method is shown in the following Table 1. 
Table 1 SWOT analysis results of electricity retailers of power grid companies

\begin{tabular}{|c|c|}
\hline Analysis contents & Results \\
\hline Strengths & 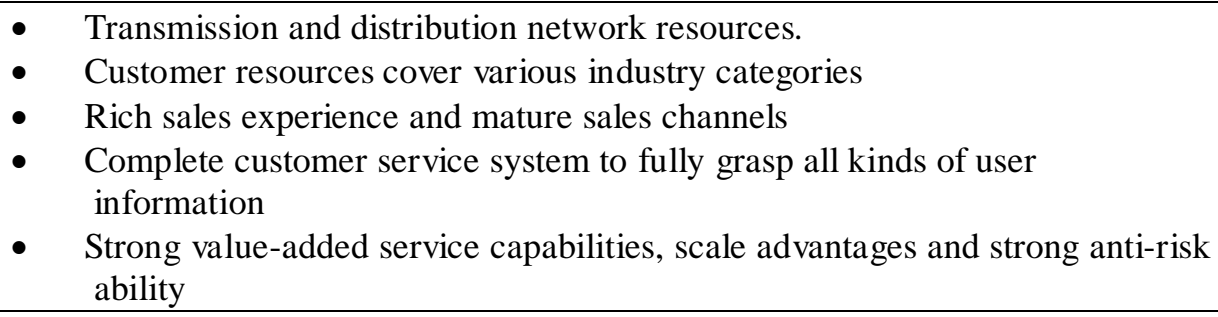 \\
\hline Weaknesses & $\begin{array}{ll}\text { - } & \text { Lack of power generation resources } \\
\text { - } & \text { Lack of competitive marketing experience } \\
\text { - } & \text { Lack of flexibility in decision-making } \\
\text { - } & \text { Relative low operating efficiency } \\
\end{array}$ \\
\hline Opportunities & $\begin{array}{ll}- & \text { Support by alternative electricity policies } \\
\text { - } & \text { Accelerated power grid construction } \\
\end{array}$ \\
\hline Threats & $\begin{array}{ll}\text { - } & \text { Certain policy restrictions } \\
\text { - } & \text { Industrial structure constraints }\end{array}$ \\
\hline
\end{tabular}

One can observe that, electricity retailers of power grid companies have all related power and customer resources other than power generation resources, they have obvious advantages in terms of internal resources. However, the original monopoly status of the power grid companies was broken due to the cultivation of the new sales entities in electricity market. And at the same time, the policies carried out some regulations and restrictions on them to develop electricity sales businesses. In short, in the early days of the reform, the overall advantages are greater than disadvantages and the threats are greater than opportunities.

\section{Assumption of Market Positioning}

According to the previous analysis, the electricity retailers of power grid companies will face greater competitive pressure in the early stage of entering the market. In order to survive and grow stronger in the fierce competition, they will not only sell electricity but also compete in full and integrated energy services.

(1) Carry out energy services

companies need to enhance the professional level in all directions, expand the extension business of power grid and introduce a scientific and rational new business mode. The integrated energy service is taken as the foothold for new business and services are carried out around the customers' integrated needs to promote the business integration and improve the level of the market-oriented energy service.

(2) Conduct bigger and stronger electricity trading

The electricity trading business is the starting point for companies' cooperation and the foundation for all energy management for users. At this stage, companies should explore various business strategies that adapt to the market mode and create dedicated energy profiles for each customer with professional classification management experience for users. Continuously optimize trading strategies and obtain the lowest price and the largest market dividend for customers with minimal uncertainty.

(3) Get involved in the data economy

The businesses of electricity retailers of power grid companies are linked upwards with the supply side and undertaken downwardly with multi-dimensional customers. Therefore, companies should focus on value-driven thinking, improve the data asset management system, tap the value of big data resources and strive to build a full energy chain data economy. To enhance the core competitiveness by using data to promote management changes and transformation.

In summary, electricity retailers of power grid companies should be positioned in modern energy service companies with an open and highly market-oriented energy chain. Companies will 
experience an evolutionary process of clear positioning, personalized service, diversified products and clustered industries, build he energy industry ecosystem gradually and finally form a highly market-oriented integrated energy service ecosystem. In this process, companies should explore the process of transformation and upgrading of energy structure, participate in the energy revolution and promote the coordinated and sustainable development of the regional economy.

\section{Summary}

In this paper, firstly, we studied the operating environment and competitive situation of electricity retailers of power grid companies under the new electric power reform. And then we applied the SWOT analysis method to determine the companies' own strengths, weaknesses, opportunities and threats. Finally, we made reasonable assumptions about the market positioning, which helps those to clearly position their own businesses on the basis of an understanding of competitiveness and seize customer resources in the sales side of the electricity to achieve long-term development.

\section{References}

[1] W. Gao: Science Technology \& Enterprise, Vol.14 (2014), p.2. (In Chinese)

[2] D.Y. Xu: Science Technology and Industrial, Vol.12 (2012) No.3, p.78. (In Chinese)

[3] C.J. Wei and W. Han: Scientific Chinese, Vol. 16 (2014), p.165. (In Chinese)

[4] T. Kang and L.P. Cao: Modern Enterprise Culture, Vol. 35 (2015), p.236. (In Chinese)

[5] J.X. Ni: Research on Market Competitiveness of Electric Power Design Enterprise Based on Quality Management System (MS., North China Electric Power University, China 2012). (In Chinese)

[6] L. Niu: Globalization, Vol. 12 (2017), p.34. (In Chinese)

[7] L. Ma, X.X. Zhang, S. Yang, S. Song and H.Y. Qu: Electric Power, Vol. 50 (2017) No.7, p.5. (In Chinese)

[8] X. Liu, C. Chen, X.T. Dong, W.L. Guan and S.Y. Pan: Electrical Engineering, Vol. 18 (2017) No.10, p.5. (In Chinese)

[9] Y. Chen: Enterprise Reform and Management, Vol. 21 (2016), p.18. (In Chinese)

[10] X.M. Xi: China Economist, Vol. 4 (2010), p.256. (In Chinese) 